\section{Conclusions from Lake Nyos disaster}

SIR - In August 1986, the Lake Nyos disaster brought death and devastation to a densely populated part of the Northwest Province of Cameroon ${ }^{1.2}$. The death toll, which was officially estimated at more than 1,700, was far in excess of that for any previous similar disaster. In the immediate aftermath many countries not only offered humanitarian assistance but also sent teams of scientists to investigate the cause of the disaster. All participants were invited to attend a conference organized by the Cameroonian Ministry of Higher Education and Scientific Research in Yaoundé in March 1987 to "find out as much as possible about the cause of the Lake Nyos disaster" and "determine the precautions which should be taken to avoid a similar tragedy in the future".

Although the scientific discussions in Yaoundé were interesting, it soon became apparent that there were irreconcilable differences between various groups concerning almost every aspect of the disaster. The final communique, which was widely circulated and subsequently published ${ }^{3}$, accurately reflected the scientific arguments but offered little sound advice to the government of Cameroon other than to suggest that more scientific studies were needed. During the meeting, a group of us set up an international working group to act as an information exchange and coordinate future research ${ }^{\dagger}$.

A seminar on the Lake Nyos gas disaster was convened on 11 September by our group to which all those who had worked on the disaster were invited. During the discussions it became apparent that a consensus had now arisen concerning the cause of the disaster and the urgent need for remedial measures to prevent a recurrence. Our main objective is to offer helpful scientific advice to the political authorities in Cameroon, but we hope that our four main conclusions, which are set out below, will also be of wider interest. 1. The 1986 disaster was caused by a massive release of $\mathrm{CO}_{2}$ from Lake Nyos. 2. Lake Nyos now contains about 300 million cubic metres of carbon dioxide and therefore remains very dangerous.

3. Further $\mathrm{CO}$ is being added at a rate of at least 5 million $\mathrm{m}^{3}$ per year and the danger is therefore increasing.

4. Another gas disaster could occur at any time, so the $\mathrm{CO}_{2}$ in Lake Nyos should be reduced as a matter of urgency.

The members of the working group considered ways in which carbon dioxide might be extracted from Lake Nyos.

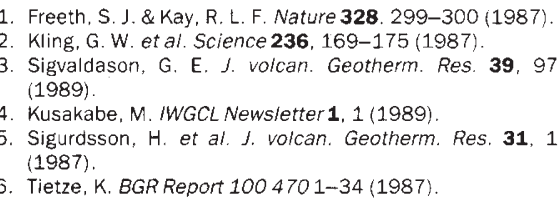

6. Tietze, K. BGR Report 100470 1-34 (1987)

There was general concern that any attempt to remove gas from the lake might itself create an unstable situation and induce a massive gas release. Before any attempt at controlled degassing, therefore, equipment should be installed to monitor the stability of the lake, and appropriate plans should be prepared to deal with any medical emergency which might arise. It is also recommended that any system of gas extraction should first be tested on Lake Monoun, $100 \mathrm{~km}$ southeast of Nyos. This lake was the source of a gas release which killed 37 people in 1984 (ref. 5 ), but as it is only half as deep as Lake Nyos it is potentially far less dangerous.

There was general agreement that pipes should be installed to remove the gas-rich bottom water from the lakes and that the degassed water should be discharged outside the lake basins, so as to avoid disturbing the natural stratification "of the lakes. Concern was expressed over the total lack of information concerning the amount of

\section{Mitogen signal}

SIR-The recent reports by Xu et al. ' and Buchberg et al. ${ }^{2}$ that the proteins encoded in the human and mouse neurofibromatosis type 1 (NF-1) genes are structurally related to the mammalian GTPaseactivating (GAP) and yeast IRA1/2 proteins immediately suggest a biochemical explanation for the aberrant proliferation of melanocytes and Schwann cells that is one of the hallmarks of NF-1. This explanation, not advanced in either report, derives directly from the demonstrated ability of cyclic AMP to trigger Schwann cell and melanocyte division.

The following features of signal transduction and Schwann cell and melanocyte biology apply: (1) GAP (in mammalian cells) and IRA1 and IRA2 (in Saccharomycetes cerevisiae) bind to small G proteins (such as Ras and Ras-related proteins), stimulate the low intrinsic GTPase activity of these proteins, and thereby inactivate them ${ }^{3}$. (2) A critical target of both Ras in yeast and the $G_{*}$ proteins of higher eukaryotes is adenylate cyclase. When complexed with GTP, these $G$ proteins activate cyclase, and thereby stimulate the synthesis of intracellular cAMP ${ }^{4}$. (3) Cyclic AMP is a strong but cell-specific mitogen for Schwann cells, melanocytes and certain other mammalian cells ${ }^{5.6}$. A key component of cAMP mitogenesis in these cells is the cAMP-dependent induction of receptors for polypeptide growth factors such as platelet-derived growth factor? These facts suggest that, just as IRA 1 and IRA2 are negative regulators of the $\mathrm{G}$ protein-cAMP pathway in yeast, so NF-1 might, in normal circumstances, stimulate the low intrinsic GTPase activity of a gas in the sediments and rocks beneath the lakes. If there are zones of gas-saturated (or near saturated) water beneath either of the lakes, then any reduction in pressure might trigger another lethal gas release". It was therefore thought prudent to recommend that the rate of water extraction should not exceed the natural recharge rate, as lowering of the water level would reduce the pressure at depth.

S.J. FREETH*

Geological Hazards Research Unit, University College of Swansea,

Swansea SA12 8PP, UK

G.W. KLING

Woods Hole, USA

M. KUSAKABE

Okayama University

J. MALEY

ORSTOM, Montpellier

F.M. TCHOUA

University of Yaoundé

BGR, Hannover

K. TIETZE

* Convenor and Chairman of the Inaugural Meeting of the International Working Group on Crater Lakes.

specialized small $G$ protein in Schwann cells and melanocytes, inactivate this $G$ protein, and inhibit the stimulation of cyclase. Thus, even partial loss-of-function mutations in the NF-1 gene would result in elevation of intracellular cAMP, upregulated expression of polypeptide growth-factor receptors, and increased Schwann-cell and melanocyte proliferation.

The problem with this hypothesis is that the only organism in which an IRA-like protein is known to regulate the cyclasestimulating activity of a small $G$ protein is $S$. cerevisiae. That the NF-1 protein might be a negative regulator of CAMP metabolism in certain mammalian cells is nonetheless consistent with the autosomal dominant genetics of NF-1 transmission, the known interaction of IRA1/2, Ras and cyclase proteins in yeast, the fact that the NF-1 protein is more similar in amino-acid sequence to IRA1 and IRA2 than to GAP itself, and the demonstration that elevation of cAMP strongly stimulates Schwann cell and melanocyte proliferation.

This hypothesis also makes two predictions that are relatively easy to test: both intracellular cAMP and the expression of cAMP-dependent genes ${ }^{*}$ should be elevated in NF-1 Schwann cells and melanocytes; and expression of the NF-1 phenotype by these cells should be growth-factor-dependent.

The Salk Institute, PO Box 85800 ,

GREG LEMKE

San Diego, California 92186-5800, USA

1. Xu. G. et al. Cell 62. 599 (1990)

2. Buchberg, A.M. et al. Nature 347, 291 (1990)

Hall. A. Science 249, 635 (1990)

Toda, T. et al. Cell 40, 27 (1985)

Raff, M.C. et al. Cell 15, 813 (1978)

Dumont. J.E. et al. Trends biochem. Sci. 14, 67 (1989)

Weinmaster, G. \& Lemke, G. EMBO J. 9, 915 (1990)

8. Monuki, E.S. et al. Science 249, 1300 (1990) 